\title{
Maria Graham: anotações sobre a flora do Brasil
}

\author{
Ariane Luna Peixoto ${ }^{1,3}$ e Tarciso de Sousa Filgueiras ${ }^{2}$
}

Recebido em 22/06/2007. Aceito em 12/02/2008

\begin{abstract}
RESUMO - (Maria Graham: anotações sobre a flora do Brasil). Dentre os 65 autores e 135 coletores que colaboraram para a grandiosa obra botânica denominada Flora Brasiliensis, coordenada inicialmente por Martius, e posteriormente por Eichler e Urban, publicada entre 1840 e 1906, participaram apenas duas mulheres: Maria Graham e a Princesa Teresa da Baviera. O presente estudo trata da contribuição de Maria Graham, que esteve no Brasil em três períodos entre 1821 e 1825, quando D. Pedro I era imperador, descreveu paisagens e coletou exemplares botânicos que foram enviados à Inglaterra, e utilizados por monografistas da dita Flora. A contribuição de Maria Graham para o estudo histórico das paisagens e aspectos da flora brasileira é pontual, porém importante. Os registros foram feitos no frescor da primeira impressão, conjugando uma observação acurada, às vezes acompanhada de iconografia. Mulher avançada para sua época, relacionava-se com a população local em situações diversas. Isto a coloca na privilegiada posição de testemunha da história daquele momento da monarquia brasileira.
\end{abstract}

Palavras-chave: coleções botânicas, descrição de paisagens, Flora Brasiliensis

ABSTRACT - (Maria Graham: notes on the flora of Brazil). Of the 65 authors and 135 collaborators of the magnificent botanical publication Flora Brasiliensis, initially edited by Martius, and later by Eichler and Urban, published between 1840 and 1906, there were only two women: Maria Graham and the princess Therese von Bayern. Here the authors discuss the contribution made by Maria Graham during her three trips to Brazil (between 1821 and 1825, under Dom Pedro I, emperor of Brazil). She described landscapes and collected botanical specimens that were sent to England and were used by monographers of the said Flora. Maria Graham's contribution to the historical study of landscapes and aspects of the Brazilian flora is limited, but very important because she was recording her first impressions at the time. Besides her interesting descriptions and objective observations, she often documented her work with artistic renditions. A woman beyond her time, Mrs. Graham cultivated the friendship of men and women alike. This puts her in the privileged position of a first-hand witness of that moment in the history of the Brazilian monarchy.

Key words: botanical collections, landscape descriptions, Flora Brasiliensis

\section{Introdução}

Nos séculos anteriores ao XX, a ciência era um mundo predominantemente de homens, sendo poucas as mulheres que se aventuraram neste campo. $\mathrm{Na}$ Botânica não foi diferente. A presença de mulheres em campo, em busca de documentação e caracterização da flora e nas múltiplas atividades de laboratório era escassa. Eram raras também mulheres que descreveram a paisagem e elementos da flora brasileira de então. A Flora Brasiliensis demonstra, com clareza, a predominância da presença masculina no âmbito das ciências botânicas à época. Idealizada e inicialmente editada por Karl Friederich Philipp von Martius e, sucessivamente editada por August Wilhelm Eichler e Ignatz Urban, esta obra trata do conjunto de espécies da flora brasileira até então conhecidas. Entre 1840 e 1906, quando foram publicadas as 40 partes, originalmente na forma de 140 fascículos, nenhum outro projeto havia reunido tantos cientistas com a finalidade de elaborar a flora de uma região (Emmerich 1994). Nesta obra são tratados 22.767 espécies das quais 5.689 eram novas para a ciência. Além das descrições são incluídas 3.811 pranchas que ilustram características de 6.246 espécies. Uma descrição da obra e suas estampas digitalizadas encontra-se em www.florabrasiliensis.cria.org.br.

Para estudar todo o acervo de espécimes coletados no Brasil, e mais aqueles que chegaram à Europa durante a elaboração dos estudos, Martius convidou 65 cientistas especialistas em taxonomia de plantas e fungos ("collaboratores"), todos europeus, dentre os quais não há um único nome feminino. Os estudos taxonômicos foram baseados em exemplares coletados por 135 colecionadores, sendo 35 alemães, 25 brasileiros, 22 ingleses, 13 franceses, 12 suecos, 10 austríacos, seis

\footnotetext{
Instituto de Pesquisas Jardim Botânico do Rio de Janeiro, Rua Pacheco Leão 915, 22460-038 Rio de Janeiro, RJ, Brasil

2 Reserva Ecológica do IBGE, C. Postal 08770, 70312-970 Brasília, DF, Brasil

Autor para correspondência ariane@jbrj.gov.br
} 
dinamarqueses, dois russos, dois belgas, dois suíços, dois italianos, um norte-americano, um espanhol, um holandês e um português (Urban 1906; Emmerich 1994).

O volume I da Flora Brasiliensis, publicado em 1906, traz a biografia dos coletores dos espécimes que serviram de base para os estudos dos diferentes grupos taxonômicos. Muitos destes coletores são bem conhecidos da maioria dos botânicos. Sobre eles Urban (1906) tece muitos comentários, tais como Martius, Saint-Hilaire, Pohl e Glaziou. Sobre outros, porém, ele diz muito pouco. Sobre Houlet informa apenas que coletou entre 1838-1839; sobre Antonio Gomes, que coletou em 1817; sobre Schornbaum que nasceu na Alemanha e morreu em Pernambuco; que Dr. Stephan, médico do séqüito da imperatriz D. Leopoldina, fez uma coleção de plantas em Minas Gerais, "prope Congonhas do Campo". Porém, duas mulheres mereceram de Urban (1906) certo destaque: Maria Graham e Therese Prinzessin von Bayern. No universo extenso de colaboradores (coletores e monografistas) há apenas estes dois nomes femininos. Esta nota faz uma breve leitura da colaboração de Maria Graham para a Botânica brasileira. As contribuições da princesa da Baviera serão analisadas posteriormente.

\section{Maria Graham}

Maria Graham nasceu no dia 19 de julho de 1785 , em Papcastle, perto de Cockermouth, na Inglaterra, filha do almirante George Dundas. Desde cedo se interessou por plantas e animais e por narrativas de viagens. Em companhia do pai, em 1808, empreendeu sua primeira viagem à Índia. No ano seguinte, desposou o capitão da Marinha Real inglesa, Thomas Graham e logo depois, com o marido, fez outra viagem ao continente indiano, regressando à Inglaterra em 1811. Juntos, passaram algum tempo na Itália, em 1819. A bordo da Fragata Doris, que o Capitão Graham comandava, vieram para a América do Sul, em 1821. Nessa ocasião visitou Pernambuco, Bahia e Rio de Janeiro. De 21 de setembro a 14 de outubro, enquanto a fragata esteve no porto de Recife, foi hóspede, por alguns dias, do governador Luiz do Rego Barreto e assistiu às primeiras lutas constitucionais.

Maria Graham chegou ao Rio em 15 de dezembro e aí permaneceu até 10 de março de 1822, quando a fragata zarpou rumo ao Chile. Em abril de 1822, perto do Cabo Horn, o esposo, que já vinha adoentado, faleceu. Enlutada, Maria Graham recolheu-se em Valparaíso, no Chile (Lago 2000). Em 15 de março de 1823 retorna ao Rio de Janeiro onde vive até outubro, a maior parte do tempo em uma casa no Morro da Glória. Nesta ocasião, ofereceu seus serviços à Imperatriz D. Leopoldina como preceptora da princesinha D. Maria da Glória, com o desejo expresso, entretanto, de ir à Inglaterra antes de assumir o encargo, com o objetivo de conseguir material didático adequado a esta atividade. Parte para a Inglaterra, retornando ao Rio de Janeiro em 4 de setembro de 1824. Durante este trajeto permaneceu por alguns dias em Pernambuco e na Bahia. Em Pernambuco, onde esteve por 15 dias, encontrou o porto bloqueado por causa de querelas relativas à Confederação do Equador. Nesta ocasião, recebeu a missão de entender-se em terra com o chefe da Rebelião, no sentido de aconselhá-lo a submeter-se ao governo do Imperador (Lima 1907).

Chegando ao Rio, assumiu o cargo de preceptora na casa imperial do Brasil, no qual permaneceu por pouco mais de um mês (de 5 de setembro a 10 de outubro de 1824). O volume 60 dos Anais da Biblioteca Nacional publica documentos (Graham 1938a; b) que trazem informações sobre as dificuldades que Maria Graham encontrou na sua função de preceptora da princesa Maria da Gloria, que veio a ser Rainha de Portugal. Lustosa (2006), escrevendo sobre D. Pedro I, retrata o ambiente da corte, repleto de intrigas palacianas, em todo o período que abrange as visitas de Maria Graham ao Brasil.

Finda essa breve ligação com a corte brasileira, Maria Graham optou por não retornar de imediato à Inglaterra, permanecendo no Rio de Janeiro até setembro de 1825. Morou, a princípio, na Rua dos Pescadores e depois nas Laranjeiras, onde se dedicava a escrever, pintar e herborizar plantas das matas das redondezas. Em 10 de setembro de 1825 deixou, definitivamente, o Brasil. No entanto, manteve vínculo com o país, através da intensa correspondência com a imperatriz, até a morte desta, em 11 de dezembro de 1826 (Garcia 1940).

Após o seu retorno à Inglaterra, contraiu segundas núpcias com o pintor Augustus Wall Callcott, em 1827, daí ser conhecida também como Lady Maria Callcott. Faleceu na Inglaterra, em 28 de novembro de 1842, aos 57 anos, de causas desconhecidas.

\section{Algumas observações e notas de Maria Graham sobre a flora brasileira}

Na Flora Brasiliensis, Urban (1906) cita que o itinerário das coletas botânicas de Maria Graham abrange, em 1821, Pernambuco (setembro), Bahia e Rio de Janeiro (dezembro); em 1823, Rio de Janeiro, caminho para Santa Cruz. Garcia (1940) complementa estas informações, afirmando haver contribuições de 1824 e 1825, ainda no Rio de Janeiro, feitas em Laranjeiras e na fazenda "Macacú", baseado no "Escorço biográfico do Imperador D. Pedro I". Este documento foi adquirido pela Biblioteca Nacional, em 1938, juntamente com outros escritos e 61 aquarelas, do livreiro/antiquário londrino 
W.T. Spencer que havia colocado à venda parte do espólio literário e artístico de Maria Graham. Os documentos relativos ao Brasil (correspondência entre Maria Graham e a imperatriz D. Leopoldina, o Escorço Biográfico de Dom Pedro I, além de outros) foram traduzidos e publicados no volume 60 dos Anais da Biblioteca Nacional (Garcia 1940).

Diferentemente de seu diário, o Escorço é uma memória narrativa sobre sua passagem pelo Rio de Janeiro, referindo-se especialmente a Dom Pedro I, D. Leopoldina e sua filha primogênita, D. Maria da Glória. Trata-se, portanto, de uma resumida biografia não autorizada do primeiro imperador brasileiro (Garcia 1940) que Maria Graham começou a escrever em 1834, logo após a morte do Dom Pedro I, concluindo-a em 1835. No Escorço há informações preciosas que dão luz a diversos temas da época e, também, às visitas aos locais onde colecionou plantas.

O Escorço e o Diário trazem, mesclados com descrições da vida em sociedade, de fatos políticos da época e outros assuntos, descrições de paisagens, algumas notas e informações botânicas. As descrições são vívidas. Campos (1996) afirma que nos seus textos Maria Graham aparece como uma pessoa ativa, dotada de intensa curiosidade, procurando se informar e fazer anotações sobre tudo o que estava ocorrendo a sua volta. Informa ainda que para os historiadores, o Diário é visto como uma fonte rica, com informações bastante precisas sobre o Brasil da época da independência.

$\mathrm{Na}$ sua primeira viagem, há referências à coleta de plantas já em Pernambuco: "Os guardas-marinha ... os mais novos ficaram comigo para colher flores, reunir plantas e, com a ajuda dos marinheiros dos barcos, dirigir os preparos para o jantar" (Diário, 9 de outubro). Na passagem pela Bahia escreve "Passeei a cavalo ...através de florestas selvagens, em que todos os esplendores da vida animal e vegetal do Brasil se exibem. A esplêndida plumagem dos pássaros, a brilhante cor dos insetos, o tamanho e forma, cor e fragrância das flores e plantas que via na maior parte pela primeira vez, encantaram-nos e tornou nosso pequeno passeio às grandes plantações de pimenteiros às quais nos dirigíamos, delicioso. As sebes estão, nesta estação, alegres com a florada de café, mas é muito cedo para a pimenteira ou algodão atingirem seu esplendor" (Diário, 23 de outubro).

As suas anotações no Diário, em 21 de dezembro, já no Rio de Janeiro, são dedicadas a uma visita ao Jardim Botânico, desde a partida logo após o nascer do sol, até Botafogo, e daí à Lagoa Rodrigo de Freitas "cercada de montanhas e florestas exceto onde uma pequena barra arenosa permite um desaguamento ocasional para o mar ... É impossível conceber algo de mais rico do que a vegetação que vem até a borda da água em volta do lago." Sobre o Jardim Botânico, informa que "Esse Jardim foi destinado pelo Rei para o cultivo de especiarias e frutos orientais e, acima de tudo, para o do chá, que ele mandou vir da China juntamente com algumas famílias acostumadas à sua cultura. Nada pode ser mais próspero do que o conjunto das plantas. $O$ cinamomo, a cânfora, a noz-moscada e o cravo-da-índia crescem tão bem quanto no solo natal. A fruta-pão produz o fruto admiravelmente, e da mesma sorte as frutas orientais, tal como foram trazidas para cá, amadurecem tão bem quanto na Índia. Notei particularmente o jambo (Jumbo malacca) da Índia e a longona (Euphoria longona), espécie de lichi da China. Fiquei desapontada por não encontrar nenhuma coleção de plantas indígenas. Contudo já se fez muita coisa para se ter esperanças de desenvolvimento futuro, quando o estado político do país for mais tranqüilo para permitir dar atenção a estas cousas." Afirma que neste dia o Sr. Langford conseguiu colecionar certo número de besouros e uma magnífica borboleta e que ela fez "um esboço imperfeito da paisagem da casa do padre". Este esboço faz parte da Coleção do Museu Britânico e é apresentado, em seu diário impresso com o título Lagoa Rodrigo de Freitas.

Nesta estada no Brasil, retornou mais uma vez ao Jardim Botânico, desta feita detendo-se predominantemente sobre a fábrica de pólvora. Entretanto dá uma preciosa informação sobre a distribuição de mudas de plantas feitas pelo Jardim Botânico. “... no Jardim Botânico há sempre um viveiro das plantas mais rarase úteis que são oferecidas, tanto a nativos quanto a estrangeiros, de modo que não somente os jardins do Brasil são abastecidos com os mais raros produtos do oriente, mas eles são levados para diversos países da Europa".

Na sua última viagem, visitou novamente o Jardim Botânico e inicia a sua anotação no diário de modo prosaico "Convidei dois rapazes brasileiros muito bonitos, que estão para entrar para a Marinha Imperial, para passar o dia no Jardim Botânico que parece estar em estado de conservação muito melhor do que quando o vi há dois anos". Além de comentar sobre o crescimento das árvores que havia visto anteriormente, informa que "Fiquei contente por ver muitas das plantas indígenas que haviam sido plantadas aqui: tais como a andraguoa, a noz de que se tira o mais forte purgativo que existe; $o$ cambucá, cujo fruto é tão grande como uma maçã russet e tem o gosto sub-ácido de groselha, com a qual sua polpa tem forte semelhança; a japetee-caba, cujo fruto é pouco inferior ao damasco, e a grumachama donde se extrai um licor, tão bom como o de cerejas" (Diário, 9 de setembro de 1823). 
Na segunda viagem ao Brasil, no Rio de Janeiro, relata com minúcias a sua expedição à Fazenda Santa Cruz "cerca de 14 léguas da cidade" ocorrida entre 20 e 26 de agosto. A Fazenda de Santa Cruz, estabelecida pelos jesuítas, foi a mais avançada e produtiva do Rio de Janeiro, em sua época. Com a expulsão dos jesuítas, passou à coroa e com a chegada da corte ao Rio, sua sede, reformada, tornou-se o palácio para o qual a família real se deslocava em períodos de descanso. Além dos ricos comentários sobre o deslocamento até Santa Cruz, a fazenda e sua administração, o trato com os escravos, Maria Graham descreve diversas paisagens, plantações e engenhos, esboça desenhos e comenta sobre as plantas: "Hoje vi flores de maracujá de cores que dantes nunca observara: verdes, róseas, escarlates, azuis; ananases selvagens de belo carmesim e púrpura; chá selvagem, ainda mais belo que o elegante arbusto chinês; palmeiras do brejo e inúmeras plantas aquáticas novas para mim" (Diário, 23 de agosto).

Logo após deixar os serviços da casa imperial, Maria Graham morou por curto espaço de tempo na Rua dos Pescadores, depois se mudou para o Vale das Laranjeiras. Diz ela: "A excelente madame Lisboa e seu digno marido emprestaram-me uma casa de campo na sua bela chácara, à entrada do vale, durante todo o tempo da minha estada no Brasil". Adiante prossegue: "Por este tempo eu me tinha estabelecido na minha casa de campo, com a preta Ana como criada, e um mulato (livre) extremamente destro na agulha, que me trazia as provisões, e segundo eu estava convencida, guardava-me a casa" (Escorço 1940). Assim que se estabeleceu, passou a usar o tempo de que dispunha para explorar as redondezas, incluindo "a floresta virgem" atrás da casa. Nesse período, esboçou desenhos de paisagens e plantas encontradas em Laranjeiras, ao mesmo tempo que coletava plantas visando obter "espécimes secos para o Dr. Hooker".

"Não muito depois de ter instalado minha gente e ter colocado meus livros e minha secretária junto à única janela de vidro da casa, encontrei para mim mesma uma ocupação, para as muitas horas de solidão que previ me aguardarem. Sempre apreciara muito as flores e o esplendor da floresta virgem atrás de minha casa, naturalmente me atraiu. Tomei emprestado do Ministro da Marinha um exemplar do Aublet e fiquei desapontada verificando que suas gravuras eram muitas vezes, imperfeitas. E que, em alguns casos ele tinha sido obrigado a estampar folhas, frutos e mesmo cálices secos, de muitas das árvores das florestas, não as tendo encontrado na estação das flores nos seus lugares nativos. Resolvi fazer desenhos de tantas quantas pudesse, obtendo, ao mesmo tempo especimens secos para o Dr. Hooker, de Glasgow ${ }^{l}$, ainda que não tivesse muitas instalações convenientes, sendo minha casa muito úmida.
Em obediência a este plano, era meu costume deixar a preta Ana representando seu papel de lavadeira e o mulato, comprando e cozinhando o meu jantar, enquanto eu ia para o mato, à procura de espécimens de arbustos floridos e árvores para meus empreendimentos botânicos." (Escorço 1940).

Durante as excursões pela floresta, tomou conhecimento da existência de um quilombo nas redondezas, cujos habitantes vendiam para sua casa ovos, aves e frutas. Ela afirma que era considerada "amiga dos pretos" que acreditavam que ela nunca delataria a existência desses núcleos quilombolas.

Relata com detalhes, uma excursão que fez a fazenda "Macacú", propriedade de amigos dela.

"Logo que saí, uma neblina rala e branca enchia todos os pequenos vales; os cumes fantásticos da serra dos Órgãos já brilhavam com muitas cores ao sol e as ricas e escuras matas entre eles prometiam muitas árvores $e$ arbustos novos para meu álbum de desenhos, se não para a coleção do Dr. Hooker. Mesmo antes de voltar para casa inventei de recolher um ramo de Bombax, inteiramente novo para mim. ... No correr da manhã tive o prazer de encontrar três espécies de Lecythis $e$ ainda algumas das excelentes castanhas que elas produzem e que nunca havia visto nem provado antes. Aubert deu uma descrição de várias espécies desse gênero, mas foi infeliz em não visitar a América do Sul numa época do ano ou em circunstâncias que lhe permitissem atribuir a cada uma o próprio fruto, flor ou folha. Aqui vi pela primeira vez o Palmito ... Pode-se supor que apreciei extremamente esta visita à mata, mas, ai de mim, o tempo era muito curto, não podia nem desenhar todas as plantas, que tão avidamente colhia, nem podia espalhá-las para secar com muita esperança de sucesso. O lugar era úmido, os insetos inumeráveis e as crianças curiosas e mexelhonas. Que mais se podia exigir para impedir a formação de um herbário!" (Escorço 1940).

Porém, de algum modo, Maria Graham superou tais dificuldades. Amostras botânicas coletadas sobreviveram aos obstáculos foram enviadas à Inglaterra e incorporadas ao acervo do herbário do Royal Botanic Gardens, Kew, na coleção denominada Herbarium Hookerianum. Fotografias de dois espécimes desta histórica coleção são apresentadas nas Fig. 1 e 2.

Maria Graham interessava-se por questões escravagistas, buscava dados sobre os navios negreiros que chegavam aos portos brasileiros e visitava os mercados. Também manifestava interesse pela política

\footnotetext{
${ }^{1}$ Garcia (1940) informa que o Dr. Hooker ao qual Maria Graham se refere é William Jackson Hooker (1788-1865), botânico inglês, professor em Glasgow de 1815 a 1839 e diretor do Jardim Botânico de Kew.
} 


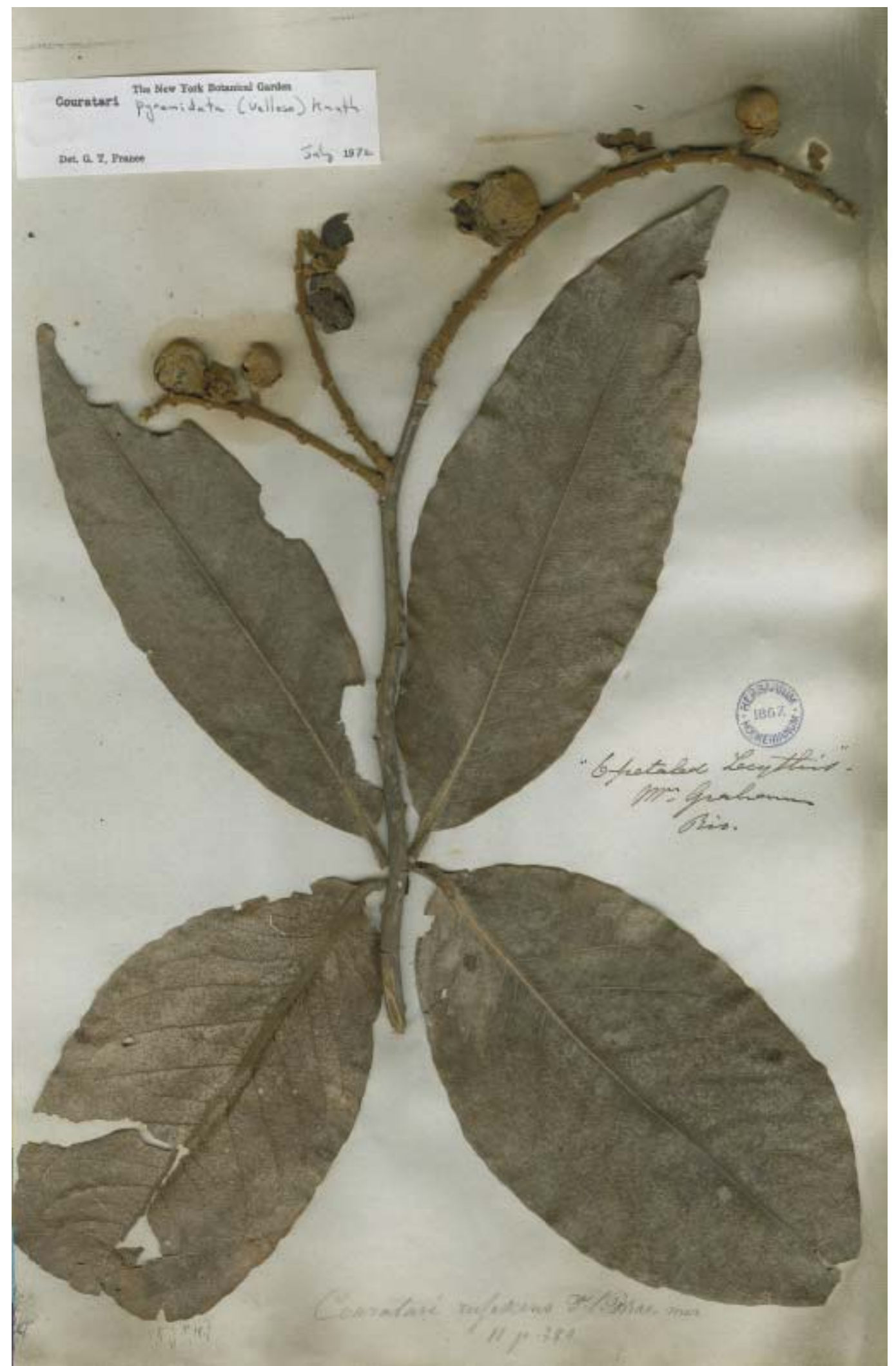

Figura 1. Exemplar herborizado de Couratari pyramidata (Vell.) Kunth depositado no Royal Botanical Garden, Kew, coletado por Maria Graham. 


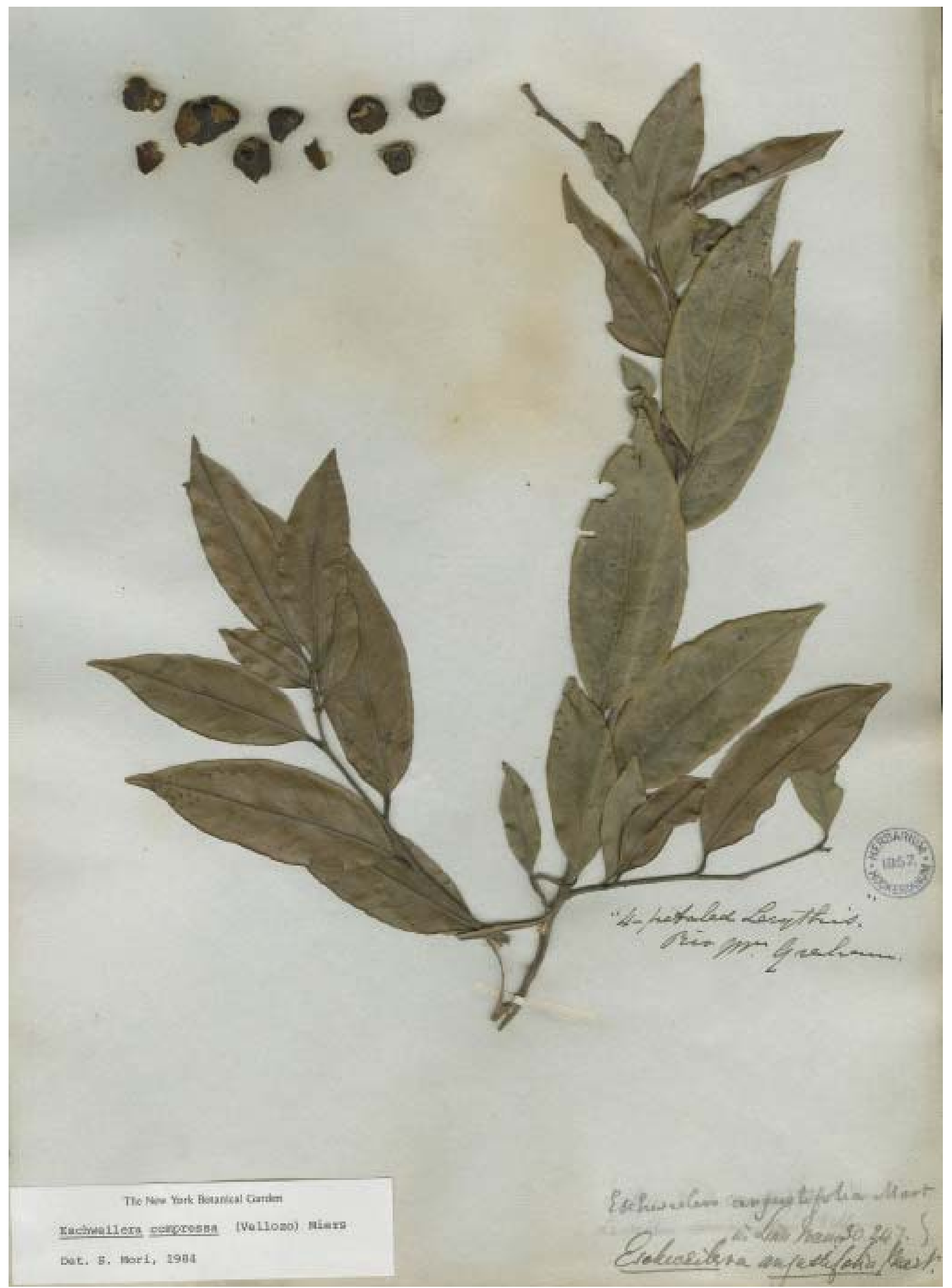

Figura 2. Exemplar herborizado de Eschweilera compressa (Vell.) Miers depositado n o Royal Botanical Garden, Kew, coletado por Maria Graham. 
interna do Brasil de então. Chegou a interferir, pessoalmente, em vários momentos sobre questões políticas de sua época (Lima 1907). A sua aguçada curiosidade por fatos da sociedade e da natureza, aliada a um forte lastro cultural é demonstrada em várias passagens dos seus escritos. Por exemplo, ao aportar em Pernambuco, na sua primeira viagem, em setembro de 1821, escreve: "o coronel recomendou-me insistentemente que ficasse a bordo. Mas eu nunca tinha visto uma cidade em estado de sítio e por isso resolvi desembarcar". Seus relatos são também ricos em observações sobre a moda na corte, as apresentações musicais e teatrais que ocorriam e a aquisição, o preparo de alimentos e os hábitos alimentares locais. Em todos esses escritos, nota-se um aguçado senso de observação, que relaciona fatos, enfatiza contornos e destaca conteúdos.

Há em seu diário um trecho que demonstra que a autora tinha clareza da importância dos eventos históricos que presenciara, na consolidação da jovem nação que ela, de certo modo, vira nascer: "É curioso que o primeiro dia em que vaguei nas costas do Brasil, no ano de 1821, tenha sido aquele em que se deu o primeiro tiro da parte dos independentes contra as tropas reais em Pernambuco e que, finalmente, deixasse o porto do Rio no mesmo dia em que a proclamação da dissolução completa da ligação entre Brasil e Portugal foi lida em todas as praças públicas e as salvas inda se disparavam para celebrar a independência final do país”. Maria Graham se coloca como testemunha da História.

A autora publicou inúmeras obras, além das anteriormente referidas, entre as quais: "Journal of a residence in India" (1812); "Journal of a voyage to Brazil and a residence there during part of the years 1821 , 1822, and 1823 (1824)" e "Scripture Herbal" (1842). Publicou também um clássico infantil denominado "Little Arthur's History of England" (1835).

A contribuição de Maria Graham para o estudo histórico das paisagens e aspectos da flora brasileira é pontual, porém assume importância quando se percebe que os registros foram feitos em forma de diário, no frescor da primeira impressão. Esses relatos tornam-se algo mais analíticos quando abordados pelo Escorço, escrito quando a autora, já distante das terras brasileiras, rememorava as experiências que aqui vivera. Relacionando-se com homens, mulheres e crianças, ela posiciona-se como uma mulher avançada para sua época, quando a grande maioria restringia-se às lides domésticas, compras, eventuais visitas familiares e comparecimento a celebrações religiosas.

\section{Agradecimentos}

Ao biólogo Edglei A. César, pela digitalização dos espécimes que ilustram esta nota e ao Kew Herbarium por permitir o acesso aos exemplares; à historiadora Begonha Bediaga pela leitura crítica do texto; ao CNPq, pela bolsa de produtividade em pesquisa concedida aos autores.

\section{Referências bibliográficas}

Campos, R.C.B. 1996. Viagem ao nascimento de uma nação. O diário de Maria Graham. São Paulo, Atual editora.

Emmerich, M. 1994. Von Martius e a Botânica. Pp. 91-99. In: R. Horch; H.W. Fauser \& W. Magenschab (orgs.). 200 anos C.F.Ph. Von Martius. São Paulo. Publ. Fundação Martius.

Lago, T. 2000. La viajera ilustrada. Vida de Maria Graham. Santiago Del Chile, Planeta.

Lima, O. 1907. Mrs. Graham e a Confederação do Equador. Revista do Instituto Arqueológico de Pernambuco 12: 306-310.

Lustosa, I. 2006. Perfis Brasileiros - D. Pedro I. Rio de Janeiro, Companhia das Letras.

Garcia, R. 1938 [1940]. Maria Graham no Brasil. Explicação. Anais da Biblioteca Nacional do Rio de Janeiro 60: 7-28.

Graham, M. 1938a [1840]. Correspondência entre Maria Graham e a Imperatriz Dona Leopoldina e Cartas anexas. In: Garcia, R. (Editor), Lacombe, A.J. (Tradutor). Anais da Biblioteca Nacional do Rio de Janeiro 60: 29-65.

Graham, M. 1938b. Escorço biográfico de Dom Pedro I, com uma notícia do Brasil e do Rio de Janeiro em seu tempo. In: R. Garcia (ed.), A.J. Lacombe (trad.). Anais da Biblioteca Nacional do Rio de Janeiro 60: 67-172.

Graham, M. 1990. Diário de uma viagem ao Brasil. [original inglês, 1824, trad. A.J.Lacombe]. São Paulo, Ed. Univ. São Paulo.

Urban, I. 1906. Vitae itineraque collectorum botanicorum, notae collaboratorum biographicae, florae brasiliensis ratio edeni choronologica, systema, index familiarum. In: K.F.P. Martius; A.W. Eichler \& I. Urban (eds.). Flora Brasiliensis, v. I, pars I. 